\title{
Research on service quality evaluation of fitness clubs based on Yate
}

\author{
Yue Wen ${ }^{1, a}$, Hua Zhong ${ }^{2, \text { b }}$, Jianfei Liu $^{2}$ and Xiaobo Zuo ${ }^{2}$ \\ ${ }^{1}$ Xi'an Physical Education University, Xi'an 710000, China \\ 232181 PLA troops, Xi'an 710032, China \\ a1016972139@QQ.com, bwoweijifen1@163.com
}

Keywords: commercial fitness club, service quality, SERVQUAL scale.

\begin{abstract}
Aim to study how to evaluate the service quality of commercial fitness clubs, this paper studies the service quality evaluation of Yate fitness clubs on the basis of SERVQUAL scale combined with interviews and questionnaires. We make correlation analysis of service quality evaluation dimensions and overall service quality, and the analysis of value function, to obtain the demand of consumers for a specific index and the effect of the index on the overall satisfaction. The results verify the validity of the SERVQUAL evaluation model, enrich and perfect the research method of service quality evaluation model, and also provide accurate and specific improvement measures for Yate club.
\end{abstract}

\section{Introduction}

With the rapid development of China's economy in recent years, commercial fitness clubs are also developing vigorously. State Sports General Administration "2016 fitness coach career development report" shows that: According to China Internet TV, the fitness market has reached 30 billion yuan, an increase of $14 \%$ over the same period of last year. The number of fitness clubs is also increasing. There are more than 10,000 fitness clubs in China, up 20\% over the same period of last year [1]. Also, the competition in fitness industry is becoming more and more intense. Business fitness clubs belong to service-oriented enterprises, and the competition among service-oriented enterprises is essentially the competition of service quality. To seek development, we need more and more consumers to go into fitness clubs and enjoy high-quality services [2]. To improve service quality, Firstly, we need to set up evaluation indicators for service quality and study the key factors that affect service quality. And then we can diagnose the problem of affecting the quality of service and make corresponding improvements. As there is no unified method to evaluate the service quality, this paper will mainly study how to evaluate the service quality of fitness clubs.

The definition of service quality began in the early twentieth Century. GRONROOS[3], a scholar in Finland, has formally put forward the concept of customer perceived service quality (referred to as service quality). Since then, many scholars have devoted themselves to the research of service quality measurement and evaluation models, and put forward many related models such as PARASURAMAN 、 ZEITHAML and BERRY's Service Quality Model[4], RUST's Three Dimensional Service Quality Structure Model[5] and BRADY's Three Dimensional Multistage Composite Structure Model[6]. In all of them, The Service Quality Model is the most representative. The model proposes that there are 10 quality factors in the service process. After that, it was revised to 5 quality factors, and finally the 5GAP model was formed. In 1988, PARASURAMAN revised the previous service quality evaluation into 5 factors: Reliability, Materiality, responsiveness, Assurance and Empathy, based on the differential theory (the difference between customers' expectations of service quality and customers' actual service from service organizations). And proposed a precise multi index service quality evaluation method model [7]. According to the model, PZB proposed the SERVQUAL scale, which contains 5 QoS determining factors and 22 observation indexes and can measure the quality of business services. This paper will use SERVQUAL evaluation model to evaluate the service quality of commercial fitness clubs. 


\section{Research objects and methods}

\subsection{Research object}

This paper takes the service quality of Xi'an Yate fitness club as the research object, based on the service quality management and service quality evaluation model. We Interviewed more than one fitness club consumers and related experts, distributed 300 questionnaires to study the quality of service, finally evaluated the service quality of the club According to the results of the survey.

\subsection{Research method}

\subsubsection{Documentation method}

By reading the relevant books on sports industry management, fitness club management and national sports policy, as well as browsing the content of fitness clubs and service quality management, we can grasp the research status and development trend of service quality management in fitness clubs at home and abroad. Refer to the papers on service quality management in the excellent doctoral and master's theses database, and use the theories and methods that have been studied for reference to apply the methods and ideas in different industries, so as to provide a theoretical basis for this paper. 2.2.2 Fieldwork and questionnaire survey method

We visit every branch of Yate fitness club in Xi'an, selected samples randomly as the basis for studying the fitness service quality. The main field visits were market operations, facilities, fitness instructors and so on. And we made a questionnaire for evaluation scale based on the fitness club service quality SERVQUAL scale and the reference to expert advice and fitness club service flow and characteristics. Besides this questionnaire also contains basic information of the surveyed members. Each store distributed 50 copies and totally not less than 300 copies. The time span is 3 to 4 months. Before this the questionnaire had passed the validity test and reliability test. Ten experts from club management and institutions of higher learning assessed the structure, content and overall situation of the questionnaire. Overall, the result shows that the design of the questionnaire reaches the initial design requirements, which is relatively scientific and complete.

In addition, the five dimensions of service quality evaluation and the overall Krenbach alpha coefficient were calculated (as shown in table 1). The results shows that $a>0.7$, what means The uniformity and reliability is very good.

Table 1 Reliability Statistics

\begin{tabular}{|c|c|c|c|}
\hline Dimensions & Quantity & Krenbach $\alpha$ & Sample Size \\
\hline Tangibility & 7 & 0.91 & 261 \\
\hline Reliability & 6 & 0.89 & 261 \\
\hline Responsiveness & 5 & 0.86 & 261 \\
\hline Security & 5 & 0.92 & 261 \\
\hline Empathy & 6 & 0.87 & 261 \\
\hline Total & 29 & 0.94 & 261 \\
\hline
\end{tabular}

\section{Results and analysis}

\subsection{Basic situation analysis of Yate fitness club service quality evaluation questionnaire}

The study began in October 2017 at 3 stores of Yate fitness club and completed in January 2018. A total of 300 questionnaires were issued, of which 289 were recovered, with a recovery rate of $96.3 \%$. And 261 valid questionnaires were collected in 289 points, accounting for $90.3 \%$ of the total number of valid questionnaires.

The result shows that the quality of Xi'an Yate fitness club's quality of service is only about 3. (as shown in table 2). The quality of service in all dimensions is relatively average, lingering in general satisfaction, and there is no outstanding service quality. What shows that the service quality of Yate fitness club in Xi'an is not high. Through the statistics of service quality score under different dimensions (as shown in table 3), we can see that there is a certain gap between the expected service 
quality of the members and the perceived service quality of the members. Which also means that the service quality of Yate fitness club does not satisfy members' expectations of the club.

Table 2 Descriptive statistics of service quality in Yate fitness clubs

\begin{tabular}{|c|c|c|c|c|c|c|}
\hline \multicolumn{2}{|c|}{ Dimensions of service quality } & $\mathrm{N}$ & MIN & MAX & AVG & SD \\
\hline $\mathrm{X}$ & Tangibility & 261 & 1.48 & 5.00 & 3.10 & 0.87 \\
1 & & & & & & \\
\hline $\mathrm{X}$ & Reliability & 261 & 1.33 & 5.00 & 3.01 & 0.97 \\
2 & & & & & & \\
\hline $\mathrm{X}$ & Responsiveness & 261 & 1.20 & 5.00 & 2.99 & 1.09 \\
3 & & & & & & \\
\hline $\mathrm{X}$ & Security & 261 & 1.40 & 5.00 & 2.89 & 0.98 \\
4 & & & & & & \\
\hline $\mathrm{X}$ & Empathy & 261 & 1.00 & 5.00 & 2.75 & 1.25 \\
5 & & & & & & \\
\hline $\mathrm{Y}$ & Perceived Service Quality & 261 & 1.28 & 5.00 & 2.95 & 0.87 \\
\hline
\end{tabular}

Table 3 Statistics of service quality score under different dimensions

\begin{tabular}{|c|c|c|c|c|c|}
\hline & Tangibility & Reliability & Responsiveness & Security & Empathy \\
\hline $\begin{array}{c}\text { Expected Service } \\
\text { Quality }\end{array}$ & 3.93 & 3.67 & 3.81 & 3.74 & 3.59 \\
\hline $\begin{array}{c}\text { Perceived Service } \\
\text { Quality }\end{array}$ & 3.10 & 3.01 & 2.99 & 2.89 & 2.75 \\
\hline D-Value & 0.83 & 0.66 & 0.82 & 0.85 & 0.84 \\
\hline
\end{tabular}

\subsection{Correlation analysis of service quality evaluation dimensions and overall service quality}

We made a correlation analysis of service quality evaluation dimensions and overall service quality (as shown in table 4). The correlation coefficients of the five dimensions are all greater than 0.7 , what means it passed the significance test. These five dimensions are closely related to the overall quality of service and can serve as criteria for judging service quality. The correlation degree of each dimension from high to low is the reliability, empathy, security, responsiveness and tangibility of quality of service.

Table 4 correlation analysis of service quality evaluation dimensions and overall service quality

\begin{tabular}{|l|c|c|c|c|c|c|}
\hline & & Tangibility & Reliability & $\begin{array}{c}\text { Responsivenes } \\
\text { s }\end{array}$ & Security & Empathy \\
\hline $\begin{array}{l}\text { Overall } \\
\text { Service } \\
\text { Quality }\end{array}$ & $\begin{array}{c}\text { Pearson } \\
\text { Correlation }\end{array}$ & 0.725 & 0.861 & 0.755 & 0.803 & 0.841 \\
\cline { 2 - 7 } & Sig.(2-tailed) & 0.000 & 0.000 & 0.000 & 0.000 & 0.000 \\
\hline
\end{tabular}

\subsection{Value function analysis of service quality of Yate fitness club}

Through the value function curve, we can understand the demand for a specific index and the impact of the index on the overall satisfaction. According to the value function curve, members can be divided into three categories: neutral, demanding and non-demanding. The satisfaction of neutral members is determined by the degree of satisfaction they expect to be satisfied. Therefore, the value function curve of them is linear. Demanding members, as the name implies, are members who require higher quality of service. They feel satisfied only when most of their needs are met. Therefore, the value function of this group is concave. Non-demanding members consume more generously, and when a small portion of their needs are met, they are satisfied. So the value function of is convex. The greater the degree of curve or concave, the greater the degree of no need or need for members. According to the validity test results of Table 5, the sample with higher scores in each dimension also had higher overall satisfaction level, which was verified again that the evaluation dimensions were consistent with the overall satisfaction level. 
Table 5 Validity test of different dimensions

\begin{tabular}{|c|c|c|c|c|c|}
\hline \multirow{2}{*}{ Dimensions } & \multicolumn{5}{|c|}{ Overall Satisfaction Level(1-5 points) } \\
\cline { 2 - 6 } & 1 points & 2 points & 3 points & 4 points & 5 points \\
\hline Tangibility & 1.27 & 2.23 & 2.96 & 3.83 & 4.46 \\
\hline Reliability & 1.35 & 2.41 & 3.08 & 3.91 & 4.61 \\
\hline $\begin{array}{c}\text { Responsivenes } \\
\text { s }\end{array}$ & 1.27 & 2.73 & 3.21 & 4.05 & 4.79 \\
\hline Security & 1.44 & 2.57 & 2.98 & 3.73 & 4.69 \\
\hline Empathy & 1.36 & 2.36 & 3.08 & 3.62 & 4.51 \\
\hline Sample Size & 9 & 30 & 116 & 87 & 16 \\
\hline
\end{tabular}

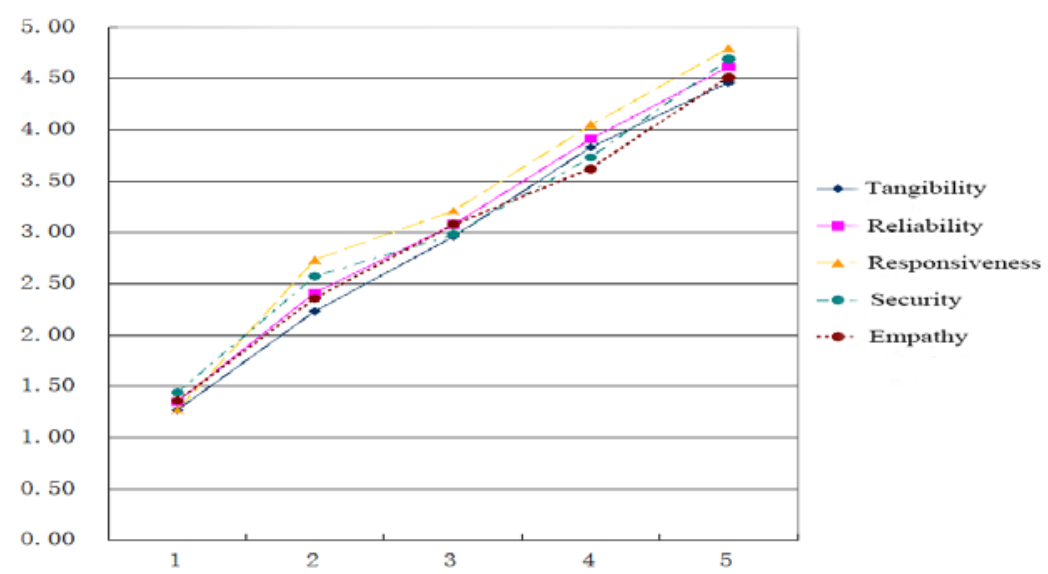

Fig.1 Value function curves of each assessment dimension

As figure 1 shown, the value function curves of the five evaluation dimensions are basically linear functions, and a few of them appear slightly concave. The inconsistency of the five curves shows that members have different requirements for fitness service quality. The degree of depression reflects that members are most demanding for responsiveness and safety. When the professional quality of employees and the professional skills of fitness coaches are greatly improved, the satisfaction of members will increase slightly. Taking into account members' needs, the management of the club should enhance the training of the professional skills of the service personnel and their coaches. They can subdivide the fitness areas and let different coaches and service personnel be responsible. Through business segmentation, they can further enhance the staff's business level and improve the overall service quality. Generally speaking, five attributes have demand, but the demand have difference.

\section{Conclusions}

Through the analysis of SERVQUAL service quality evaluation model, we can conclude that the members don't have a high opinion of the overall service quality of Yate Club. The five dimensions of the overall service quality evaluation together determine the overall service quality. Members have a certain degree of demand for the five dimensions. In detail, members have the greatest demand for the safety and responsiveness of the club, indicating that members' consumption ability, fitness awareness and education level have gradually increased, and the professional requirements for employees and fitness coaches have become increasingly demanding. Yate club is in urgent need of providing corresponding personalized services and enhancing the competitive advantage.

\section{References}

[1] State Sports General Administration Vocational Skill Appraisal Guidance Center, Research Report on fitness coach career development in 2016, R. Beijing: China national professional fitness coach professional meeting. 2016: 1-35. 
[2] LiYan Wang, Effect Analysis of Service Quality of Commercial Fitness Club on Consumer Satisfaction, J. Journal of Hanjiang University in 2018, 2018: 46-2.

[3] GRONROOS C. Strategic management and marketing in the service sector, R. Helsinki: Swedish School of Economics and Administration, 1982: 83-104.

[4] PARASURAMANA, ZEITHAMLVA, BERRYLL. A conceptual model of service quality and its implications for future research, J. Journal of Marketing,1985,49(4)41-50.

[5] RUSTRT, OLIVERRL. Service quality: insights and managerial implications from the frontier, M. New York: Sage Publication,1994:1-19.

[6] BRADYMK, CRONINJR, JOSEPHJ. Customer orientation effects on customer service perceptions and outcome behaviors , J. Journal of Service Research,2001,3(3):241-251.

[7] Hao Wang, Evaluation of express service quality, D. Hubei University,2014. 